\title{
Review: Computer-based clinical decision support systems can improve physician performance in some areas
}

Hunt DL, Haynes RB, Hanna SE, Smith K. Effects of computer-based clinical decision support systems on physician performance and patient outcomes. A systematic review. JAMA. 1998 Oct 21;280;1339-46.

\section{Question}

Do computer-based clinical decision support systems (CDSSs) affect physician performance and patient outcomes? (A CDSS was defined as software designed to aid in clinical dectsion making, with individual patient data matched to a knowledge base to generate patient-specific assessments or recommendations.)

\section{Data sources}

This study updates a 1994 review. Trials published from 1974 to March 1998 were identified by searching MEDLINE, EMBASE/Excerpta Medica, INSPEC (International Information Service for the Physics and Engineering Communities), Science Citation Index, the Cochrane Library, bibliographies of relevant studies, and by contacting authors.

\section{Study selection}

Studies were included if participants were health professionals in clinical practice or postgraduate training, clinician per-

\section{Commentary}

The use of CDSSs in clinical setungs is a logical extension of technology designed to assist health care systems and physicians to cope with information overload. The large and heterogeneous body of relevant literature has been comprehensively and rigorously reviewed by Hunt and colleagues. The results show the capacity of CDSSs to improve care processes in a range of health care settings, particularly for preventive care reminders, drug dosing, efficient test ordering, and for dissemination and implementation of care guidelines (1). However, despite an improvement in the quality of studies of such outcotnes, there is less evidence about improvements in diagnosis or patient outcomes.

formance or patient outcomes were assessed, and data were collected prospectively for patient care with a CDSS compared with care without a CDSS.

\section{Data extraction}

Data were extracted on patient characteristics, setting, intervention, and outcomes. 2 authors independently assessed each study for methodologic quality.

\section{Main results}

68 studies (59 randomized controlled trials) met the inclusion criteria and had sufficient data for analysis. The studies assessed CDSSs related to intravenous medication and warfarin dosing $(n=15)$, diagnostic aids (e.g., for chest or abdominal pain) $(n=5)$, preventive care reminders (e.g., vaccinations or cancer screening) $(n=19)$, and other aspects of medicai care $(n=29)$. Meta-analysis was not possible because of study differences in clinical problems, participants, interventions, and outcomes. The results were presented in terms of whether a statistically significant effect was reported.

Effectiveness of computer-based clinical decision support systems (CDSSs)

\begin{tabular}{lcc}
\hline CDSS topic & $\begin{array}{c}\text { Number of studies reporting } \\
\text { improved clinician performance }\end{array}$ & $\begin{array}{c}\text { Number of studies reporting } \\
\text { improved patient outcomes }\end{array}$ \\
\hline Drug dosing & $9 / 15$ & $1 / 5$ \\
Diagnosis & $1 / 5$ & $1 / 1$ \\
Prevention & $14 / 19$ & $0 / 1$ \\
Other & $19 / 26$ & $4 / 7$ \\
\hline
\end{tabular}

The generalizability of results from CDSS studies is a major issue. Many of the successful studies were done in centers rich in veteran clinician advocates, content experts, and administrative support for CDSSs. It is likely that unreported fallures of CDSSs without such facilitating conditions exist.

CDSS establishment costs and clinician acceptability are critical factors that have received little evaluation to date. Only Tiemey and colleagues (2) showed potental savings, and clinician time to use CDSSs has been found to both increase (2) and decrease (1). Before CDSS systens prolifexate at considerable expense, much better information on factors that predict their success or falure is required.
43 of the 65 studies $(66 \%)$ that as sessed clinician performance reported some benefit (Table). 6 of 14 studies that assessed patient outcomes reported some benefit (Table). Of the 8 studies that reported no benefit, 5 had $<80 \%$ power to detect a moderate and clinically important improvement.

\section{Conclusions}

Computer-based clinical decision support systems can improve physician performance related to drug dosing, preventive care, and other aspects of medical care. Effects on patient outcomes have not been sufficiently studied.

Source of funding: Healtb Eordence Applatation and Linkage Netwonk (Conadian Network of Contres of Excellowte Program).

For conrespondence: Dr R.B. Haynes, Rom 3H7, MaMaster University Medical Conrr, 1200 Main Stret West, Homilton, Ontoris L8N 3Z5, Canada. TAX 905-546-0401.

Abstract and Commentary also published in ACP 7oumal Chab. 1999;130:79.
7 osepline Wedh Queen Elizabeth Hutint Bring Smith, MBDS Oniversity of Adath Woodoille, South Austalia, Anstita

\section{References}

1. Safran C, Rind DM, Davis RB, et al Gudelines for management of HIV infertion with computer-based patients reosil Lancet. 1995; 346:341-6.

2. Tierney WM, Miller ME, Overhage ML $^{\text {M }}$ McDonald CJ. Physician inpatient of writing on microcomputer workstangs Effects on resource utilization. JAMA. WM. 269.379 .83 